\title{
IEDITORIAL
}

\section{Perivascular adipose tissue as the secret behind resistance to atherosclerosis exhibited by the human internal mammary artery}

\author{
Tomasz P. Mikołajczyk¹, Tomasz J. Guzik¹,2 \\ 1 Department of Internal and Agricultural Medicine, Faculty of Medicine, Jagiellonian University Medical College, Kraków, Poland \\ 2 BHF Centre for Excellence Institute of Cardiovascular and Medical Sciences, University of Glasgow, Glasgow, United Kingdom
}

RELATED ARTICLE

by Kowalówka et al, see p. 1215

Correspondence to: Tomasz]. Guzik, MD, PhD, FRCP, Department of Internal and Agricultural Medicine, Faculty of Medicine, Jagiellonian University Medical College, Kraków, Poland phone: +48126330003 , email: t.guzik@uj.edu.pl Received: November 15, 2020 Accepted: November 16, 2020 Published online: December 23, 2020. Kardiol Pol. 2020; 78 (12): 1194-1196 doi:10.33963/KP.15718

Copyright by the Author(s), 2020
Perivascular adipose tissue (PVAT) is defined as adipose tissue (AT) surrounding most of blood vessels in humans. ${ }^{1}$ It is the source of adipokines produced mainly by adipocytes as well as cytokines, in turn produced by inflammatory resident cells. These molecules are important in the regulation of vascular physiology and their dysregulation is critical in cardiovascular pathologies.

In physiological setting, PVAT exhibits anti-inflammatory, anticontractile, and antioxidant effects. ${ }^{1}$ Vascular diseases are associated with remodeling of PVAT, which is linked with altered phenotype of adipocytes characterized by proinflammatory, pro-oxidative, and profibrotic properties. ${ }^{1,2}$ This change of phenotype may be responsible for recruitment of immune cells to PVAT. ${ }^{3}$ Clinical studies confirmed that the phenotype of both epicardial fat (EF) and pericardial fat $(\mathrm{PF})$ is modified in patients with coronary artery disease (CAD) and their transcriptome is clearly different when compared with subcutaneous fat (SF). ${ }^{4-6}$ The key pathways characterizing EF from patients with CAD include genes involved in the regulation of endothelial function, coagulation, immune signaling, potassium transporter, and apoptosis. ${ }^{7}$ Epicardial AT is also characterized by insulin resistance, high inflammatory chemokine production, and low differentiation ability in patients with CAD. ${ }^{6}$ Similarly, pericardial adipose tissue, which is located close to the myocardium and coronary arteries, is strongly associated with atrial fibrillation after coronary artery bypass graft (CABG) surgery, independently of many traditional risk factors. ${ }^{8}$
Recently, it has been shown that pericardial adipose tissue coordinates the activation of immune cells, granulopoiesis, cardiac fibrosis, and preservation of ventricular function in response to myocardial infarction. ${ }^{4}$ The mechanisms of these important clinical prognostic effects remain not fully defined. Moreover, characteristics of PVAT surrounding other arteries such as the internal mammary arteries (IMA) used in revascularization are much less known. In this issue of Kardiologia Polska (Kardiol Pol, Polish Heart Journal), Kowalówka et $\mathrm{al}^{9}$ report significantly higher omentin-1 (ITLN1) expression in perivascular adipose tissue surrounding the IMA (PVAT-IMA) in comparison with other fat depots including EF, PF, and SF samples in patients with severe $C A D$ undergoing $C A B G$ surgery. This finding is of interest given the fact that ITLN1 has anti-inflammatory and antiatherogenic properties and may play a potentially beneficial role in cardiovascular disorders. ${ }^{10}$ Plasma omentin levels are independently and inversely associated with intima-media thickness and increased adiponectin levels in patients with type 2 diabetes, characterized by high CVD risk..$^{10}$ Interestingly, ITLN1 expression appears to be lower in EF surrounding coronary segments with stenosis in comparison with those without stenosis in patients with CAD whereas adiponectin EF mRNA levels did not differ between stenotic and nonstenotic segments supporting protective effects of ITLN1 in CAD. ${ }^{11}$ In this context, data provided by Kowalówka et $\mathrm{al}^{9}$ suggest that high levels of ITLN1 in PVAT-IMA may provide a valuable explanation for why IMA does not develop atherosclerosis. This may also explain 


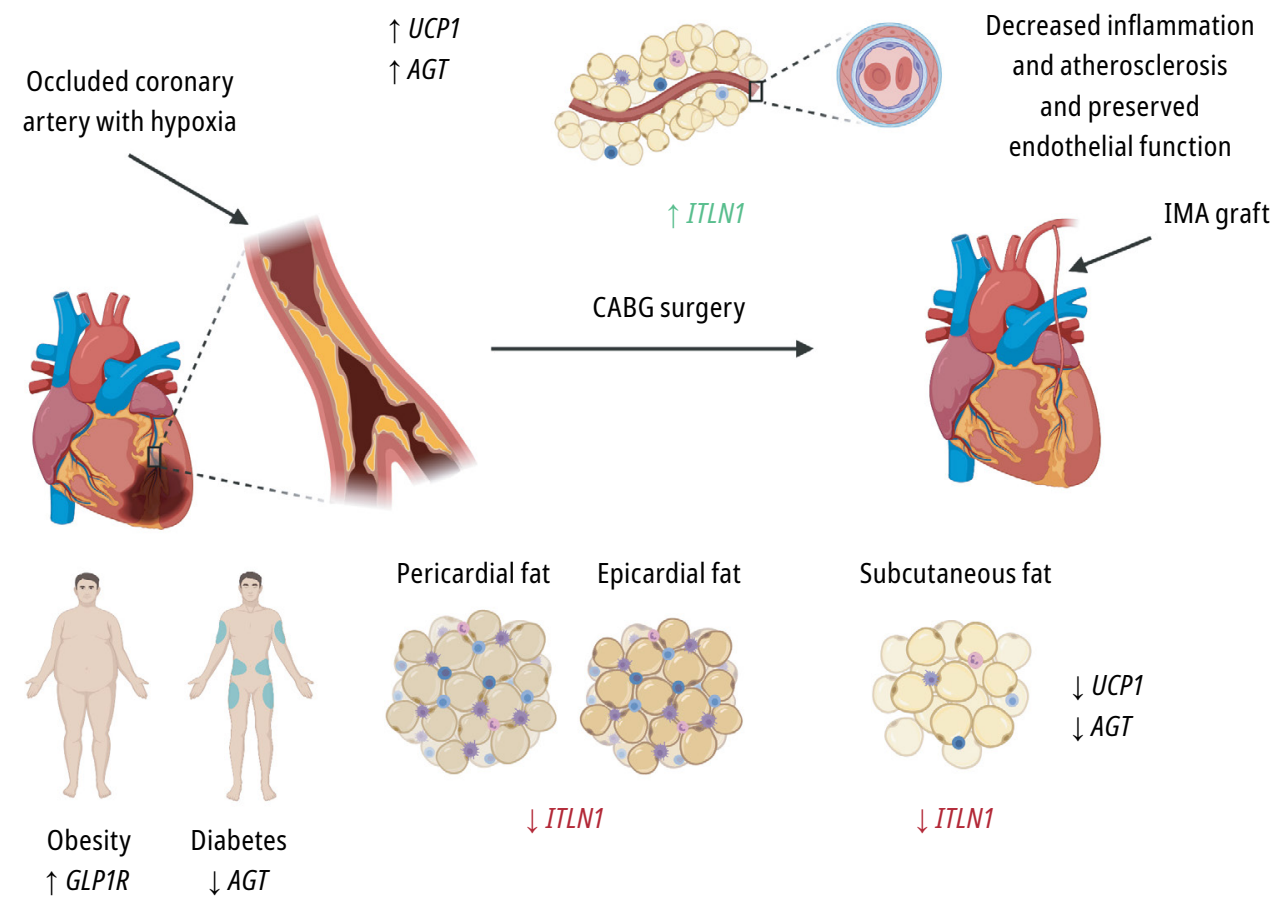

FIGURE 1 Proposed concept of the role of perivascular adipose tissue of the internal mammary artery in patients with severe coronary artery atherosclerosis. Comparison of selected gene expressions in different adipose tissue samples including perivascular fat (PVAT) of the internal mammary artery (IMA), pericardial, epicardial, and subcutaneous fat depots collected from patients undergoing coronary artery bypass graft surgery (CABG). See the text for a detailed description. This figure was created with BioRender.com.

Abbreviations: AGT, angiotensinogen; $\downarrow$, decreased expression; GLP1R, glucagon-like peptide type 1 receptor; $\uparrow$, increased expression; ITLN1, omentin-1; UCP1, uncoupling protein 1

superior long-term patency and improved survival in patients undergoing CABG using IMA when compared with saphenous veins.

Several explanations have been proposed so far for the reason why the IMA is resistant to atherosclerosis. These include its structural properties of the endothelium, such as fewer fenestrations, lower intracellular junction permeability, greater expression of antithrombotic molecules, and higher production of nitric oxide and lower expression of selectins and other adhesion molecules..$^{12}$ Interestingly, Kowalówka et $\mathrm{al}^{9}$ also described higher expression of uncoupling protein 1 (UCP1) and angiotensinogen (AGT) in PVAT-IMA in comparison with SF. UCP1 is known to play a role in nonshivering thermogenesis, especially in brown adipose tissue. ${ }^{5}$ UCP1 mRNA expression is higher in visceral adipose tissue than in SF and is suppressed by inflammatory agents and enhanced by agents improving metabolic status, suggesting that loss of UCP1 in visceral adipose tissue may contribute to the pathogenesis of obesity-related metabolic diseases. ${ }^{13}$ The high expression of angiotensinogen in PVAT-IMA may be surprising, as it represents a key step in the activation of the renin-angiotensin-aldosterone system ${ }^{1}$ and its overexpression induces white adipose tissue inflammation, glucose intolerance, and systemic insulin resistance. ${ }^{14}$ It is therefore even more intriguing that Kowalówka et $\mathrm{al}^{9}$ found lower expression of AGT in patients with diabetes in comparison with normoglycemic subjects. They also reported lower expression of adiponectin (ADIPOQ) in PVAT-IMA compared with PF. This difference may emphasize an atypical, brownor beige-type phenotype of PVAT surrounding the IMA characterized by higher UCP1 expression and lower level of classic adipokines such as adiponectin. This could suggest that protection from atherosclerosis and remodeling could be conveyed in the IMA by omentin and UCP1 rather than by more typically protective adiponectin. At the same time, Kowalówka et al ${ }^{9}$ report higher GLP1R expression in adipose tissue in obese patients in comparison with nonobese individuals.

Unfortunately, the main limitation of this study is lack of a control group, which would be possible for studies of EF and PF. It is also very interesting to speculate if levels of circulating biomarkers, for example, omentin- 1 and 
adiponectin should be measured to have a better insight into the pathomechanisms of the observed phenomenon.

The proposed concept of the dual role of PVAT in patients with severe coronary artery atherosclerosis is presented in FIGURE1. It is evident that while the number of differentially expressed adipocyte-specific molecules may explain protection of the IMA from atherosclerosis and remodeling, PVAT-IMA as well as PF and EF are rendered dysfunctional in the context of advanced $C A D$.

\section{ARTICLE INFORMATION}

DISCLAIMER The opinions expressed by the author are not necessarily those of the journal editors, Polish Cardiac Society, or publisher.

CONFLICT OF INTEREST None declared.

OPEN ACCESS This is an Open Access article distributed under the terms of the Creative Commons Attribution-NonCommercial-NoDerivatives $4.0 \mathrm{In}$ ternational License (CC BY-NC-ND 4.0), allowing third parties to download articles and share them with others, provided the original work is properly cited, not changed in any way, distributed under the same license, and used for noncommercial purposes only. For commercial use, please contact the journal office at kardiologiapolska@ptkardio.pl.

HOW TO CITE Mikołajczyk TP, Guzik TJ. Perivascular adipose tissue as the secret behind resistance to atherosclerosis exhibited by the human internal mammary artery. Kardiol Pol. 2020; 78: 1194-1196. doi:10.33963/KP.15718

\section{REFERENCES}

1 Mancio J, Oikonomou EK, Antoniades C. Perivascular adipose tissue and coronary atherosclerosis. Heart. 2018; 104: 1654-1662.

2 Desai MY. Noninvasive detection of perivascular inflammation by coronary computed tomography in the CRISP-CT study and its implications for residual cardiovascular risk. Cardiovasc Res. 2019; 115: e3-e4.

3 Mikolajczyk TP, Nosalski R, Szczepaniak P, et al. Role of chemokine RANTES in the regulation of perivascular inflammation, T-cell accumulation, and vascular dysfunction in hypertension. Faseb J. 2016; 30: 1987-1999.

4 Horckmans M, Bianchini M, Santovito D, et al. Pericardial adipose tissue regulates granulopoiesis, fibrosis, and cardiac function after myocardial infarction. Circulation. 2018; 137: 948-960.

5 Madonna R, Massaro M, Scoditti E, et al. The epicardial adipose tissue and the coronary arteries: dangerous liaisons. Cardiovasc Res. 2019; 115: 1013-1025.

6 Díaz-Rodríguez E, Agra RM, Fernández ÁL, et al. Effects of dapagliflozin on human epicardial adipose tissue: modulation of insulin resistance, inflammatory chemokine production, and differentiation ability. Cardiovasc Res. 2018; 114: 336-346.

7 McAninch EA, Fonseca TL, Poggioli R, et al. Epicardial adipose tissue has a unique transcriptome modified in severe coronary artery disease. Obesity (Silver Spring). 2015; 23: 1267-1278.

8 Drossos G, Koutsogiannidis CP, Ananiadou 0, et al. Pericardial fat is strongly associated with atrial fibrillation after coronary artery bypass graft surgery. Eur J Cardiothorac Surg. 2014; 46: 1014-1020.

9 Kowalówka A, Machnik G, Deja M, et al. Perivascular adipose tissue from the internal mammary artery in patients with severe coronary artery atherosclerosis. Kardiol Pol. 2020; 78: 1215-1220.

10 Nishimura M, Morioka T, Hayashi M, et al. Plasma omentin levels are inversely associated with atherosclerosis in type 2 diabetes patients with increased plasma adiponectin levels: a cross-sectional study. Cardiovasc Diabetol. 2019; 18: 167.

11 Du Y, Ji Q, Cai L, et al. Association between omentin-1 expression in human epicardial adipose tissue and coronary atherosclerosis. Cardiovasc Diabetol. 2016; 15: 90.

12 Otsuka F, Yahagi K, Sakakura K, Virmani R. Why is the mammary artery so special and what protects it from atherosclerosis? Ann Cardiothorac Surg. 2013; 2: 519-526.

13 Lim J, Park HS, Kim J, et al. Depot-specific UCP1 expression in human white adipose tissue and its association with obesity-related markers. Int J Obes (Lond). 2020; 44: 697-706.

14 Kalupahana NS, Massiera F, Quignard-Boulange A, et al. Overproduction of angiotensinogen from adipose tissue induces adipose inflammation, glucose intolerance, and insulin resistance. Obesity (Silver Spring). 2012; 20: 48-56. 